\title{
Determination of Vitamin D, Vitamin B12 and Folic Acid Deficiency Prevalence Among Geriatric Palliative Care Patients
}

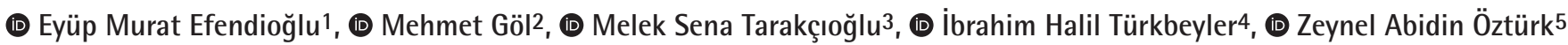 \\ 1 Ersin Arslan Education and Research Hospital, Clinic of Internal Medicine, Gaziantep, Turkey \\ ${ }^{2}$ Gaziantep University Faculty of Medicine, Department of Physiology, Gaziantep, Turkey \\ ${ }^{3}$ Gaziantep University Faculty of Medicine, Department of Biochemistry, Gaziantep, Turkey \\ ${ }^{4}$ Ersin Arslan Education and Research Hospital, Clinic of Internal Medicine, Division of Geriatric Medicine, Gaziantep, Turkey \\ ${ }^{5}$ Gaziantep University Faculty of Medicine, Department of Internal Medicine, Division of Geriatric Medicine, Gaziantep, Turkey
}

\begin{abstract}
Objective: The more advanced age, the higher incidence and prevalence of chronic diseases. Both vitamin D and B12 deficiency are common health problems affecting geriatric patients. In this study, we aimed at determining the prevalence of vitamin D, B12 and folic acid deficiency among geriatric patients hospitalised in our palliative care clinic.
\end{abstract}

Materials and Methods: Records of geriatric patients hospitalised between August 2017 and August 2018 were analysed. A total of, 100 patients (53 female and 47 male) were included in the study.

Results: The mean age of the patients was $65.48 \pm 6.40$ years. Five percent of the patients were diagnosed with vitamin $D$ insufficiency, $86 \%$ with vitamin D deficiency; 32\% and 62\% had vitamin B12 and folic acid deficiency, respectively.

Conclusion: As it is the case throughout the world, vitamin D insufficiency/deficiency is common in Turkey. In our study, the prevalence of vitamin D, B12 and folic acid deficiency was determined to be high among geriatric palliative care patients. It is predicted that well-balanced nutrition along with vitamin D and B12 and folic acid supplementation can improve the quality of life of geriatric palliative care patients and their relatives.

Keywords: Vitamin D, vitamin B12, folic acid, palliative care

\section{Introduction}

"Palliativa" in Latin means inclusiveness and protectiveness. Palliative care is a nursing approach that aims at increasing the life quality of patients manifesting life-threatening and incurable diseases $(1,2)$.

Vitamin $D$ is a steroid hormone which has substantial importance to maintain calcium phosphorus balance and accordingly bone health $(3,4)$. As in all age groups, vitamin D deficiency is critical problem for those, aged 65 and above. Vitamin D is substantial for physiological functioning of nervous, cardiovascular, respiratory and immune systems, maintenance of metabolism and healthiness of bones $(5,6)$. Recently, several diseases have been found to be associated with vitamin D deficiency. For instance, Diabetes Mellitus, cancers and cardiovascular diseases are revealed to be allied with low vitamin D levels. Also, vitamin D deficiency undoubtedly paves the way for decreased muscle strength power, depression, functional disability, increased fall risk and fractures (7).

More or less one billion people throughout the world exhibit low vitamin D levels. Forty to $100 \%$ of U.S. and European community dweller elderly population have lower vitamin $D$ levels than normal $(8,9)$. Determination of vitamin $D$ level is recommended in all elders (10).

Vitamin B12 is a water-soluble vitamin. Vitamin B12 deficiency prevalence varies between five and $60 \%$ in several studies. It is found to be lower in elders who are living socially active

Address for Correspondence: İbrahim Halil Türkbeyler, Ersin Arslan Education and Research Hospital, Clinic of Internal Medicine, Division of Geriatric Medicine, Gaziantep, Turkey

Phone: +90 5054882185 E-mail: ihturkbeyler@gmail.com ORCID: orcid.org/0000-0002-5489-1692

Received: Aug 19, 2019 Accepted: Feb 13, 2020

Cite this article as: Efendioğlu EM, Göl M, Tarakçıoğlu MS, Türkbeyler ï, Öztürk ZA. Determination of Vitamin D, Vitamin B12 and Folic Acid Deficiency Prevalence Among Geriatric Palliative Care Patients. Eur J Geriatr Gerontol 2020;2(1):9-12

๑Copyright 2020 by the Academic Geriatrics Society / European Journal of Geriatrics and Gerontology published by Galenos Publishing House. 
(12\%) and higher among elders with a kind of health problem or living in a nursing home (30 46-40\%) (11). The aetiology vitamin B12 deficiency is compromised by mainly two factors. First one is inadequate intake in nutrition and the latter is reduced absorption through intestine. Vitamin B12 deficiency chiefly leads to cardiovascular diseases, neural tube defects and persistent or progressive pathologies of both central and peripherical nervous system, besides famous haematological disorders. It may cause psychiatric manifestations before hematologic or neurologic symptoms in geriatric age group. While hematologic symptoms regress in response to treatment, neurologic symptoms may remain to be unresolved (12).

Folate is also an important, soluble vitamin in B-complex group which cannot be synthesized in human body. Folate deficiency usually emerges from insufficient intake and prompts certain disorders to develop, such as megaloblastic anemia, major depression, cardiovascular diseases, Alzheimer's disease and increases the risk of some carcinomas. Symptoms, such as headache, weakness, fatigue, irritability, being unable to concentrate, shortness of breath and palpitation can be experienced in case of folate deficiency, as well (13-15). According to "Turkey Nutrition and Health Survey 2010", folate intake is definitively lower than assumed optimal amount among individuals between the age of 15 and 17 and women aged 65 and above in comparison to other age groups (16).

The purpose of this study is to determine the prevalence of vitamin D, B12 and folate deficiencies among geriatric palliative care patients.

\section{Materials and Methods}

This is a cross-sectional and retrospective study. The medical file and electronic records of geriatric patients hospitalised for one year, since $1^{\text {st }}$ of August 2017 till $1^{\text {st }}$ of August 2018, were analysed. Totally, 100 patients, 53 of whom were women and 47 were men, included in the study. Diagnoses of the patients were registered. Vitamin D, B12 and folate levels of the patients were reached by using the laboratory results in records. Vitamin D deficiency was defined by serum $25(\mathrm{OH})$ D level less than $20 \mathrm{ng} /$ $\mathrm{mL}(<20 \mathrm{ng} / \mathrm{mL})$ whereas vitamin $D$ insufficiency was referred to the $25(\mathrm{OH}) \mathrm{D}$ level varying between 21 and $29 \mathrm{ng} / \mathrm{mL}(\geq 21 \mathrm{ng} /$ $\mathrm{mL}, \leq 29 \mathrm{ng} / \mathrm{mL}$ ) (8). Vitamin B12 levels lower than $200 \mathrm{pg} / \mathrm{mL}$ were accepted as vitamin B12 deficiency. Folic acid deficiency was identified when the level was lower than $4.6 \mathrm{ng} / \mathrm{Ml}$ (17).

\section{Statistics}

After conducting questionnaires, the data acquired was recorded into the SPSS 20.0 (Statistical Package for Social Sciences) software and analysed. As all groups formed for analysis provided a pile of continues variables with normal distribution, all descriptive statistics were defined as mean \pm standard deviation.

\section{Results}

The mean age of the patients was $65.48 \pm 6.40 .47 \%$ of total were men (47 individuals) and 53\% were, women (53 individuals). The lower limits of normal range for vitamin D, B12 and folic acid were verified as $30 \mathrm{ng} / \mathrm{mL}, 200 \mathrm{pg} / \mathrm{mL}$ and $4.6 \mathrm{nmol} / \mathrm{L}$, respectively. While $5 \%$ of the patients (5 individuals) were diagnosed with vitamin D insufficiency, 86\% (86 individuals) were diagnosed as vitamin D deficient. 32\% (32) of the patients exhibited B12 deficiency and 62\% (62) folate deficiency. Among all patients in our palliative care patients, 21\% had been hospitalized due to malignancy, $16 \%$ due to cerebrovascular diseases, and 16\% due to decubitus ulcer, $14 \%$ due to neurodegenerative diseases (dementia or Parkinson's disease or both), 12\% due to Diabetes Mellitus, $12 \%$ due to chronic lung diseases and $9 \%$ due to heart failure (Table 1).

\section{Discussion}

Over the past century, the improvement of living conditions, technology and science as well an increase in the elderly population has continued. Every patient has the right to spend the last days of life in a certain quality and peace of mind. Palliative care is therefore considered among human rights values today. In this study, the levels of vitamin D, Vitamin B12 and folic acid were retrospectively examined in geriatric patients in the palliative care unit of our hospital. Our study is important because it is the first study to investigate the levels of vitamin D, Vitamin B12 and folic acid in geriatric patients in palliative care in our country. As a result of our study; $5 \%$ of the patients were diagnosed with vitamin D insufficiency; $86 \%$ were diagnosed as vitamin D deficiency. $32 \%$ and $62 \%$ exhibited vitamin B12 and folic acid deficiencies, respectively.

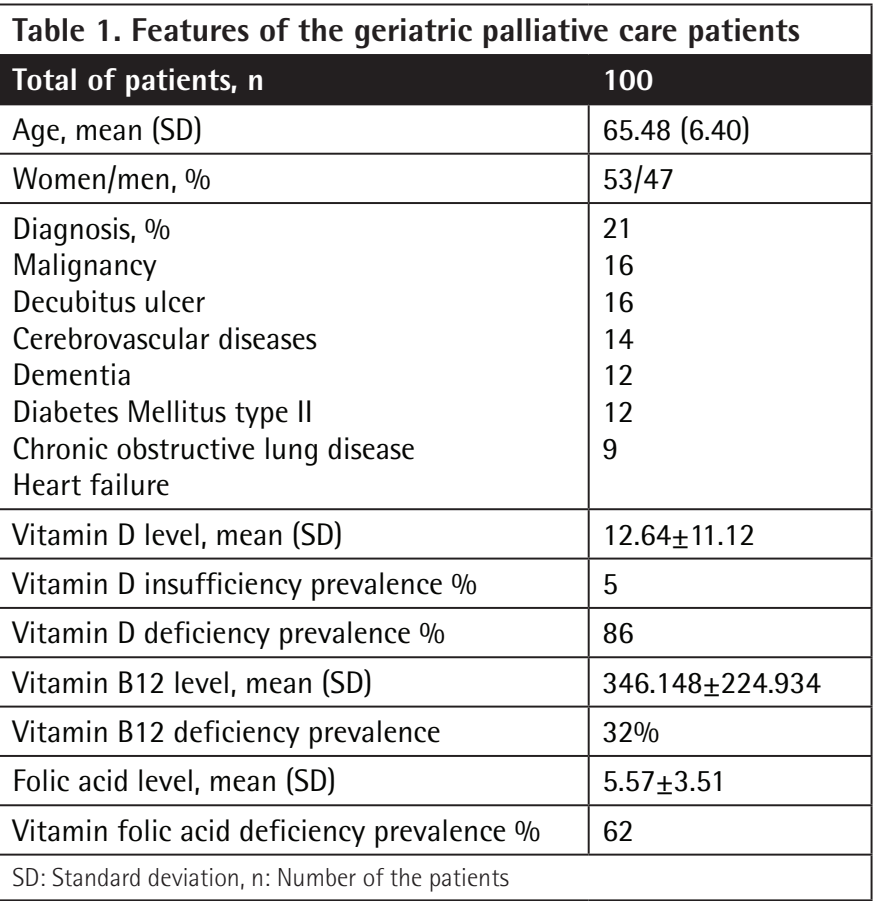


Vitamin D insufficiency/deficiency is common both in Turkey and throughout the world. Relationship between vitamin D levels and fractures is extraordinarily an object of curiosity (18). On the other hand, some brand-new roles have been provided for vitamin D. For instance, Vitamin D is also proposed to restore mitochondrial dysfunction and alleviate oxidative stress and inflammation. Thus, even a hypothesis based upon vitamin D deficiency/insufficiency and ageing coupling is brought forward (19). There also seems to be an inverse correlation between 25 $(\mathrm{OH}) \mathrm{D}$ level and both type I and II Diabetes Mellitus (20). Some observational studies indicate that vitamin D insufficiency/ deficiency may contribute to pathological basis of cardiovascular risk factors such as hypertension, hyperlipidaemias and obesity and certain diseases such as ischemic heart diseases and stroke (21). With all these diseases, chronic pain patients can also admit to clinics as having a low in vitamin $D$ alone (22).

A recent study in England uncovers that 50\% of adult population have vitamin $D$ insufficiency whilst 16\% purely have vitamin D deficiency (23). Among women aged 80 or above, vitamin $D$ insufficiency/deficiency is found to be presented with a high prevalence, up to $80 \%$ as much. Even among healthy adolescents the prevalence is to found to be approaching as a high value as $42 \%$ (24). There are only a few studies displaying vitamin D status of elderly individuals in Turkey. In one of them, 33.4\% of elderly individuals are detected to be vitamin $\mathrm{D}$ deficient (25). We also reached a high prevalence of vitamin D deficiency among both adult and elderly Turkish population in the south-eastern part of Turkey, as high as $75 \%(<20 \mathrm{ng} /$ $\mathrm{mL}$ ), in one of our previous studies. (26). In our study, 5\% of geriatric palliative care patients displayed insufficiency and 86\% were strictly vitamin D deficient. In our study, it was concluded that the reason for the relatively high incidence of vitamin $D$ deficiency in palliative care patients was due to high malnutrition, immobility, and inability to benefit from the sun in palliative care patients.

Increased oxidative stress, risk of fracture, chronic pain, Diabetes Mellitus and cardiovascular disease prevalence are associated with vitamin D deficiency in palliative care, so screening of vitamin $D$ levels in geriatric patients and supplementation if it is below acceptable range would have a very plausibly low cost if we consider benefits of patients exhibiting before mentioned diseases.

The metabolisms of folic acid and vitamin B12 intersect during the transfer of the methyl group from five-methyltetrahydrofolate to homocysteine catalyzed by B12-dependent methionine synthase. Vitamin B12 and folic deficiencies mostly arise from malabsorption. Vitamin B12 and folic deficiencies are commonly seen in elders because of both dietary inadequacy and high incidence of atrophic gastritis (27-29).
Folate and/or vitamin B12 deficiency may have additive effects in many diseases including, anemia, weakness and confusion, memory deficits, shortness of breath, peripheral neuropathy, pregnancy complications, depression, cardiovascular diseases, stroke, myelopathy, sensory and motor disturbances, ataxia, cognitive decline leading to dementia, malignancies, and psychiatric disorders $(17,28)$.

There are only a few studies displaying, vitamin B12 and folate status of elderly individuals in Turkey. Yıldırım and colleagues revealed that $62.2 \%$ of elders aged between 60 and $74,72.2 \%$ of elders aged between 75 and 84 and $50 \%$ of elders aged 85 and above are diagnosed as B12 deficient. Also, they declared that $10.4 \%$ of elders aged between 60 and $74,12.2 \%$ of elders aged between 75 and 84 and 20\% of elders aged 85 and above are diagnosed with folate deficiency (30). In our study, 32\% and 62\% exhibited vitamin B12 and folic acid deficiencies, respectively. In our study, it was concluded that the reason for the relatively high incidence of vitamin B12 and folic acid in palliative care patients was due to high malnutrition.

Several limitations of the current study need to be discussed. The main limitations of our study are as follows: the retrospective character of the study was one of leading limiting aspect. It should be supported by prospective studies. Also, our study consisted of data obtained from a single center. Moreover, for folic acid, vitamin B12 and vitamin D, only the first laboratory values of the patient's hospital intake assessment were considered. Detailed evaluation of folic acid, vitamin B12 and vitamin D status of geriatric patients in palliative care hospitalization is important and the results of prospective studies may be guiding.

\section{Conclusion}

We found that vitamin D, folic acid and vitamin B12 deficiencies were high in elderly patients hospitalized in palliative care. In consideration of increased risk and frequency of fracture, psychiatric disease, dementia, falls, cardiovascular diseases, stroke, anemia, chronic fatigue, malignancy in elderly patients in palliative care; screening and reducing vitamin $D$, folic acid and vitamin B12 deficiencies will be a step that does not require much cost but has a high return on the quality of life of patients in palliative care.

\section{Ethics}

Ethics Committee Approval: Approval was obtained from Gaziantep University Local Ethics Committee (01.08.2018/2018/203).

Informed Consent: Informed consent was not taken.

Peer-review: Internally peer-reviewed. 


\section{Authorship Contributions}

Concept: I.H.T., Design: Z.A.Ö., Data Collection or Processing: E.M.E., Analysis or Interpretation: I.H.T., Literature Search: M.G., Writing: M.S.T.

Conflict of Interest: No conflict of interest was declared by the authors.

Financial Disclosure: The authors declared that this study received no financial support.

\section{References}

1. Lorenz KA, Lynn J, Dy SM, Shugarman LR, Wilkinson A, Mularski RA, Morton SC, Hughes RG, Hilton LK, Maglione M, Rhodes SL, Rolon C, Sun VC, Shekelle PG. Evidence for improving palliative care at the end of life: a systematic review. Ann Intern Med 2008;148:147-159.

2. Sepulveda C, Marlin A, Yoshida T, Ullrich A. Palliative Care: the World Health 197 Organization's global perspective. Journal of pain and symptom management 2002;24:91-96.

3. Holick MF. Vitamin D deficiency in 2010: health benefits of vitamin D and sunlight: a 200 D-bate. Nature reviews Endocrinology 2011;7:73-75.

4. Holick MF, Binkley NC, Bischoff-Ferrari HA, Gordon CM, Hanley DA, Heaney $\mathrm{RP}$, Murad MH, Weaver CM; Endocrine Society. Evaluation, treatment, and prevention of vitamin D deficiency: an Endocrine Society 203 clinical practice guideline. The Journal of clinical endocrinology and metabolism 2011;96:1911-1930.

5. MacLaughlin J, Holick MF. Aging decreases the capacity of human skin to produce 206 vitamin D3. The Journal of clinical investigation 1985;76:15361538.

6. Boucher BJ. The problems of vitamin d insufficiency in older people. Aging and 208 disease 2012;3:313-329.

7. Gerdhem $\mathrm{P}$, Ringsberg KA, Obrant KJ, Akesson K. Association between 25-hydroxy 210 vitamin D levels, physical activity, muscle strength and fractures in the prospective 211 population-based OPRA Study of Elderly Women. Osteoporosis 2005;16:1425-1431.

8. Holick MF. Vitamin D deficiency. The New England journal of medicine 2007;357:266-281.

9. Holick MF. Vitamin D: important for prevention of osteoporosis, cardiovascular heart 217 disease, type 1 diabetes, autoimmune diseases, and some cancers. Southern medical journal 2005;98:1024-1027.

10. Mursu J, Robien K, Harnack $\amalg$, Park K, Jacobs DR, Jr. Dietary supplements and 220 mortality rate in older women: the lowa Women's Health Study. Arch Intern Med 2011;171:1625-1633.

11. Andrés $E$, Loukili $N H$, Noel $E$, Kaltenbach $G$, Abdelgheni $M B$, Perrin $A E$, Noblet-Dick M, Maloisel F, Schlienger JL, Blicklé JF. 223 Vitamin B12 (cobalamin) deficiency in elderly patients. CMAJ 2004;171:251-259.

12. Serefhanoglu S, Aydogdu I, Kekilli E, Ilhan A, Kuku I. Measuring holotranscobalamin $226 \mathrm{II}$, an early indicator of negative vitamin B12 balance, by radioimmunoassay in patients with 227 ischemic cerebrovascular disease. Annals of hematology 2008;87:391-395.
13. Gropper SS, Smith JL. Water-Soluble Vitamins. Advanced Nutrition and Human 229 Metabolism. 6th ed. Yolanda Cossio, 2013, pp 307-371.

14. Reynolds EH. Folic acid, ageing, depression, and dementia. Bmj 2002;324:1512-1515.

15. Ford ES, Byers TE, Giles WH. Serum folate and chronic disease risk: findings from a 233 cohort of United States adults. International journal of epidemiology 1998;27:592-598.

16. Pekcan $G A$, Şanlıer N, Baş $M$, Başoğlu $S$, Tek NA, Aksoy M, Başoğlu $S$, Beyhan Y, Garipağaoğlu M, Özçelik AÖ, Tayfur M, Yıldıran H. Türkiye Beslenme 235 Rehberi (TÜBER) Kayhan Ajans; 2016.

17. Blom HJ, Smulders Y. Overview of homocysteine and folate metabolism. With special 237 references to cardiovascular disease and neural tube defects. Journal of inherited metabolic disease 2011;34:75-81.

18. Group D. Patient level pooled analysis of 68500 patients from seven major vitamin D 240 fracture trials in US and Europe. Bmj 2010;340:b5463.

19. Berridge MJ. Vitamin D deficiency accelerates ageing and age-related diseases: a novel hypothesis. The Journal of physiology 2017;595:68256836.

20. Takiishi T, Gysemans C, Bouillon R, Mathieu C. Vitamin D and diabetes. Rheumatic 244 diseases clinics of North America 2012;38:179-206.

21. Skaaby $T$, Thuesen BH, Linneberg A. Vitamin D, Cardiovascular Disease and Risk 246 Factors. Advances in experimental medicine and biology 2017;996:221-320.

22. Cannell JJ, Hollis BW, Zasloff M, Heaney RP. Diagnosis and treatment of vitamin D 248 deficiency. Expert Opin. Pharmacother 2008;9:107-118.

23. Pearce $\mathrm{SH}$, Cheetham TD. Diagnosis and management of vitamin $\mathrm{D}$ deficiency. Bmj 2010;340:b5664.

24. Bandeira F, Griz L, Dreyer P, Eufrazino C, Bandeira C, Freese E. Vitamin D 252 deficiency: A global perspective. Arquivos brasileiros de endocrinologia e metabologia 2006;50:640-646.

25. Atli T, Gullu S, Uysal AR, Erdogan G. The prevalence of Vitamin D deficiency and 255 effects of ultraviolet light on Vitamin D levels in elderly Turkish population. Arch Gerontol Geriatr 2005;40:53-60.

26. Öztürk ZA, Gol M, Türkbeyler IH. Prevalence of vitamin D deficiency in otherwise 258 healthy individuals between the ages of 18 and 90 years in southeast Turkey. Wien Klin 259 Wochenschr 2017;129:854-855.

27. Dietary supplement fact sheet. Folate. Health Information. Office of Dietary 261 Supplements. US National Institutes of Health, 2014.

28. Weinstein SJ, Hartman TJ, Stolzenberg-Solomon R, Pietinen P, Barrett MJ, Taylor PR, Virtamo J, Albanes D. Null association between prostate cancer and serum folate, vitamin $\mathrm{B}(6)$, vitamin $264 \mathrm{~B}(12)$, and homocysteine. Cancer Epidemiol Biomarkers Prev 2003;12:1271-1272.

29. Botez Ml. Folate deficiency and neurological disorders in adults. Med Hypotheses 1976;2:135-140.

30. Yildirim T, Yalcin A, Atmis V, Cengiz OK, Aras S, Varli M, Atli T. The prevalence of 268 anemia, iron, vitamin B12, and folic acid deficiencies in community dwelling elderly in 269 Ankara, Turkey. Archives of gerontology and geriatrics 2015;60:344-348. 